\title{
Bmp4-directed nuclear cyan fluorescent protein provides a tool for live imaging and reveals cellular resolution of Bmp4 expression patterns during embryogenesis
}

\author{
CHUAN-WEI JANG ${ }^{1}$, LIANG GAO ${ }^{2,4}$, MARY E. DICKINSON ${ }^{1,2,4}$ and RICHARD R. BEHRINGER* ${ }^{* 1,3}$ \\ ${ }^{1}$ Program in Developmental Biology, ${ }^{2}$ Department of Molecular Physiology and Biophysics, Baylor College \\ of Medicine, ${ }^{3}$ Department of Genetics, University of Texas M.D. Anderson Cancer Center and \\ ${ }^{4}$ Department of Bioengineering, Rice University, Houston, Texas, USA
}

\begin{abstract}
The genesis of hair follicles in mammals involves multiple inductive and suppressive signaling interactions between epithelial cells and the underlying mesenchymal tissue. Bmp4 (Bone Morphogenetic Protein 4) is expressed in the mesenchymal tissue surrounding developing hair follicles. The BMP signaling pathway is suggested to play a suppressive role in hair follicle induction. In addition, it is also found to be important for specification of different cell types in mature hair follicles. Knowledge of the precise expression pattern of Bmp4 during hair follicle differentiation should provide insights into how these suppressive and differentiative roles regulate hair follicle development. However, in situ hybridization studies do not provide sufficient cellular resolution, and three-dimensional reconstructions of serial sections are tedious. We have targeted a nuclear-localized cyan fluorescent protein (CFP) reporter into the endogenous Bmp4 locus. Nuclear CFP expression was detected in embryonic tissues in a Bmp4-specific pattern, including lateral mesoderm, limb bud, dorsal optic cup, lung bud epithelium, heart outflow tract, otocyst, branchial arches, nasal pits, mammary buds, vibrassa and hair follicles. In developing hair follicles, the nuclear CFP reporter provided precise cellular resolution of Bmp4 expression patterns. These mice provide a novel tool for visualizing Bmp4 expression patterns in live and fixed tissues with cellular resolution. In addition, these studies reveal a novel view of the arrangement and dynamic changes of Bmp4-expressing cells of different stage hair follicles.
\end{abstract}

KEY WORDS: BMP4, fluorescent protein, hair follicle, live imaging

\section{Introduction}

Bone morphogenetic proteins (BMPs) are a group of secreted signaling molecules belonging to the transforming growth factorbeta superfamily (Hogan, 1996). BMPs signal through binding of receptor kinase proteins on the cell membrane and trigger transcriptional regulation of downstream effector genes (Derynck and Zhang, 2003). BMP4 is one of the most broadly expressed BMPs and has been implicated to play important roles in an array of biological processes and the genesis of many organ systems (Bitgood and McMahon, 1995, Zhao, 2003). The generation of novel fluorescent protein variants that localize to various subcellular locations provides new opportunities to examine develop- mental expression patterns (Hadjantonakis and Papaioannou, 2004). Here we report the generation of a new Bmp4 knock-in allele in the mouse that labels the nuclei of $B m p 4$-expressing cells with a CFP. The CFP expression pattern in $B m p 4^{C F P}$ mice was found to mimic the known Bmp4 expression pattern in mouse embryos. The cellular resolution provided by this allele offers a novel view of $B m p 4$ expression patterns. Specifically, we used these mice to analyze the cellular pattern of $B m p 4$ expression in developing hair follicles of the fetal mouse skin. The dynamic and

Abbreviations used in this paper: BMP, bone morphogenetic protein; CFP, cyan fluorescent protein.

*Address correspondence to: Richard R. Behringer. Department of Genetics, 1515 Holcombe Blvd. Unit 1010, Houston, TX 77030, USA. e-mail: rrb@mdanderson.org

Supplementary Material for this paper (three videos) is available at: http://dx.doi.org/10.1387/ijdb.092911cj 
reiterative changes in the pattern of Bmp4-expressing cells in developing hair follicles suggest complex roles for BMP4 at different stages of hair follicle development.

\section{Results}

Generation of a nuclear cyan fluorescent protein (CFP) knock-in allele of Bmp4 in the mouse

We originally designed the $B m p 4$ knock-in allele to simultaneously mark the cell nuclei of Bmp4-expressing cells and the secreted BMP4 ligand with different fluorescent proteins and observe the structure of BMP4 morphogen gradients in vivo. Therefore, we targeted the endogenous $B m p 4$ allele with a gene construct comprising two different fluorescent proteins in mouse embryonic stem (ES) cells (Fig. 1A). In the targeted allele, a human histone $\mathrm{H} 2 \mathrm{~b}$-fused CFP gene is inserted at the endogenous translational start codon. The expressed histone $\mathrm{H} 2 \mathrm{~b}$-fused fluorescent protein (FP) will be incorporated into chromatin and serves as a nuclear and mitotic chromosome marker (Hadjantonakis and Papaioannou, 2004). A yellow fluorescent protein (YFP) is inserted in frame into the coding sequence of BMP4 after the furin cleavage site, so that the
A

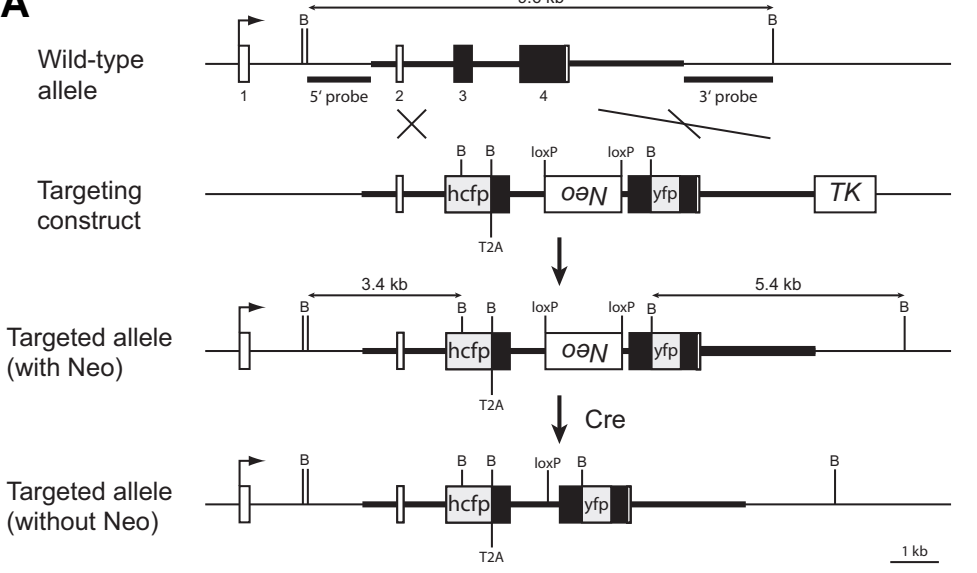

B
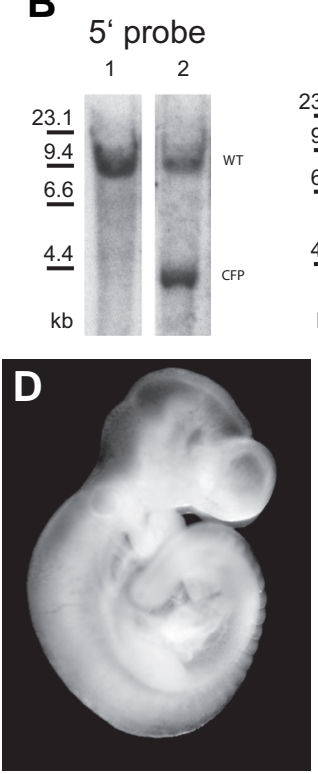

C

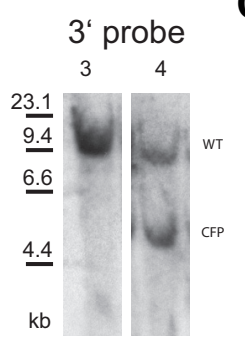

Primer set A

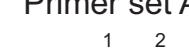

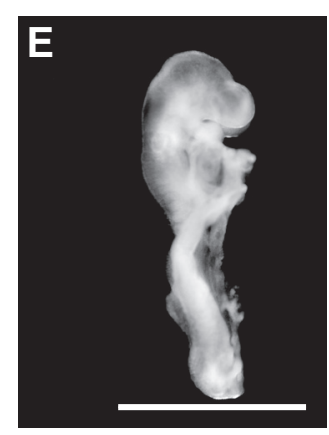

\section{Primer set B}

TABLE 1

\section{GENETIC TEST OF BMP4CFP ALLELE FUNCTION}

\begin{tabular}{ccccc} 
Parental Genotypes & \multicolumn{4}{c}{ Number of Live Born Pups of Specific Genotypes } \\
\hline$B m p 4^{C F P /+} \times \mathrm{Bmp}^{\mathrm{LacZ} /+}$ & $B m p 4^{+/+}$ & $B m p 4^{\mathrm{LacZ} /+}$ & $B m p 4^{C F P /+}$ & $B m p 4^{\mathrm{LacZ} / C F P}$ \\
$(\mathrm{a})$ & 14 & 14 & 13 & 0 \\
$B m p 4^{C F P /+} \times \mathrm{Bmp}^{C F P /+}$ & $B m p 4^{+/+}$ & $B m p 4^{C F P /+}$ & $B m p 4^{C F P / C F P}$ \\
$(\mathrm{~b})$ & 15 & 26 & 26 & 0 \\
\hline
\end{tabular}

(a) Total $n=40$ from 7 litters. (b) Total $n=41$ from 6 litters.

mature BMP4 peptide will have an N-terminal YFP tag. A similar fluorescent protein tagging strategy was used for the DrosophilaBMP4 orthologue Dpp to observe morphogen gradients in the wing maginal disc by overexpression of the chimeric protein (Teleman and Cohen, 2000). Between the H2b-CFP and BMP4YFP coding sequences, a self-cleavage viral $2 \mathrm{~A}$ peptide sequence was incorporated to mediate co-expression and posttranslational separation of the two gene products (Szymczak and Vignali, 2005). Thus, Bmp4-expressing cells should be marked in their nuclei with CFP and the BMP4 ligand tagged with YFP should be secreted and function as a wild-type allele.

We successfully targeted the construct into the endogenous locus in ES cells and generated mice bearing the allele named $B m p 4^{C F P}$ (Fig. $1 \mathrm{~B}$ and C). The neomycin resistance (neo) expression cassette was then removed by crossing to the Sox2-Cre mouse line (Hayashi et al., 2003), and all experiments were conducted on mice with the neo cassette removed. Unfortunately, $B m p 4^{C F P}$ proved to be a functionally null allele. $B m p 4^{L a c Z}$ is a null allele that has part of the $B m p 4$ coding sequence replaced by a beta-galactosidase reporter gene (Lawson et al., 1999). We were unable to recover any live born animals with a $B m p 4^{C F P /}$ $\angle a c Z$ genotype in crosses between $B m p 4^{C F P /+}$ and $B m p 4^{L a c Z /+}$ animals (Table 1 ). In addition, we could not recover any live born $B m p 4 C F P / C F P$ animals in intercrosses of $B m p 4^{C F P /+}$ mice (Table 1). Bmp4CFP/ ${ }_{C F P}$ embryos show growth retardation at E9.5 (embryonic day 9.5) (Fig. 1E), resembling the homozygous Bmp4 null phenotype (Winnier et al., 1995). Although CFP expression was readily observed in $B m p 4^{C F P / t}$ mice (see below), no YFP fluorescence was detected, suggesting that undetectable levels of BMP4 are produced from the targeted allele. However, Bmp $4^{C F P /+}$

Fig. 1. Generation of Bmp4 ${ }^{C F P}$ knock-in allele and homozygous phenotype. (A) Gene targeting strategy. The wild-type Bmp4 allele contains four exons, labeled by numbers below. The floxed Neo cassette is removed by Cre expression in the mouse germ line. A $5^{\prime}$ probe and a $3^{\prime}$ probe are used to identify correctly targeted ES cell clones. Hcfp: histone H2b-CFP; Neo: Pgk-Neo-bpA positive selection cassette; TK: MC1-thimidine kinase negative selection cassette; $B$ : BamHI sites. (B) Southern analysis of BamHI-digested genomic DNA isolated from ES cells. Lanes 1 and 3, wild-type controls, lanes 2 and 4 correctly targeted clone (clone 2C9) used to generate germline chimeras. (C) PCR genotyping results of tail DNA. Primer set $A$ allows for differentiation between wild-type, CFP and LacZ alleles. Lanes 1 and 2, Bmp4 ${ }^{\mathrm{CFP} /+}$ and Bmp4 $4^{\mathrm{LaCZ} /+}$ animals, respectively. Primer set $B$ allows for detection of the deletion of Neo cassette in the targeted allele. Lanes 3 and 4 , heterozygous animals carrying one CFP allele before and after Cre-mediated deletion of the Neo selection cassette, respectively. (D) E9.5 wild-type embryo. (E) E9.5 Bmp4CFP/CFP embryo, showing growth retardation. Scale bar, $1 \mathrm{~mm}$. 

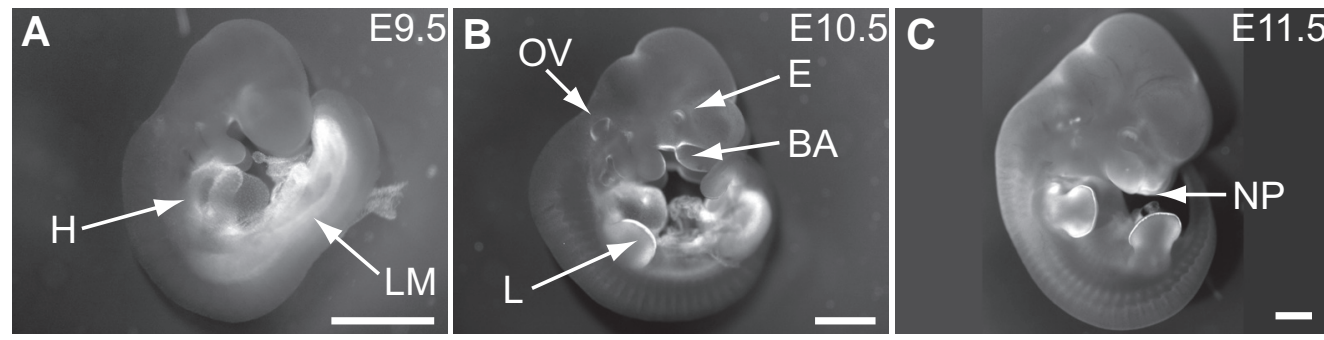

Fig. 2. CFP signal observed in known Bmp4-expressing tissues. Different stage Bmp4 ${ }^{\mathrm{CFP} /+}$ heterozygous embryos imaged under fluorescent stereo microscope with CFP filters. The embryos are at $E 9.5$ (A), E10.5 (B), E11.5 (C), E12.5 (D), E13.5 (E), E14.5 (F) stages. Arrows
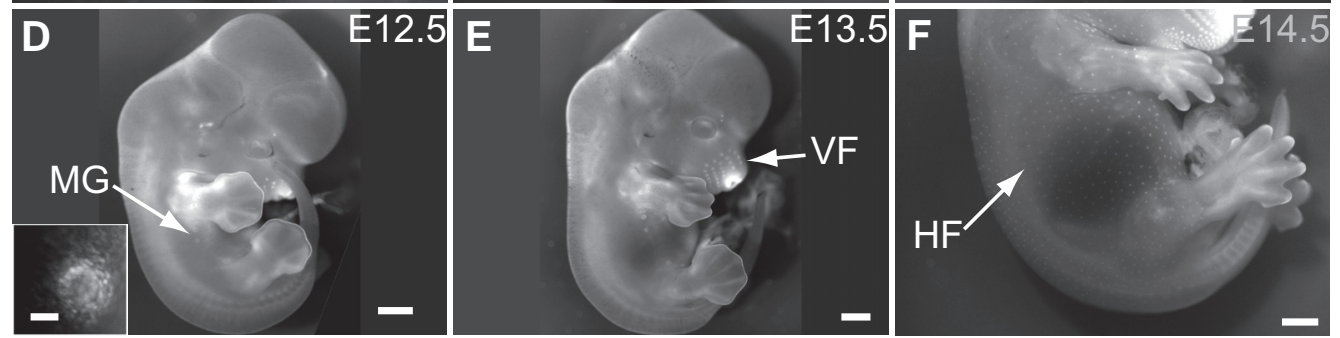
point to the CFP signal positive tissues/ organs that are known to express Bmp4 $B A$, branchial arches; $E$, eye; H: heart; $H F$, hair follicle; $L$, limb; $L M$, lateral mesoderm; $M G$, mammary gland; NP, nasal pit; OV, otic vesicle; VF, vibrissa follicle. Scale bars, $1 \mathrm{~mm}$. Insert in (D) shows a higher magnification view of mammary gland; scale bar, $100 \mu \mathrm{m}$.

heterozygous animals appear normal and are fertile. Hence, we focused our study on the nuclear CFP signal patterns in the heterozygous animals.

\section{CFP expression patterns in Bmp4 $4^{\mathrm{CFP} /+}$ are consistent with Bmp4 expression}

Because H2b-CFP has been inserted into the Bmp4 locus, expression should be under the control of the endogenous $B m p 4$ regulatory elements. Thus, the fluorescent signal in $B m p 4^{C F P /+}$ animals should reflect the endogenous $B m p 4$ expression pattern and agree with expression studies observed by other methods, i.e. in situhybridization or X-gal staining with a lacZ knock-in allele (Lawson et al., 1999). We examined whole embryos or specific fetal organs at different stages and observed CFP signals in the known Bmp4-specific expression patterns.

Prior to E9.5, CFP signals in Bmp4CFP/t embryos were either undetectable or very weak. In the E9.5 $\mathrm{Bmp} 4^{C F P /+}$ embryo, the CFP signal is strong in the lateral mesoderm and the developing heart (Fig. 2A), in agreement with a previous report (Jones et al., 1991). In the early stage limb bud, Bmp4 is expressed in both the mesoderm and the apical ectodermal ridge (AER), and, together with other BMPs, plays key roles in skeletal genesis and patterning in the limb (Bandyopadhyay et al., 2006, Maatouk et al., 2009, Selever et al., 2004). The CFP signal in the E10.5 11.5 Bmp4 ${ }^{C F P /+}$ embryo shows strong expression in the AER and the broader expression domains in the limb mesoderm (Fig. 2B and 3B). Bmp4 was also shown to be essential for patterning and development of the eye (Behesti et al., 2006, Furuta and Hogan, 1998). In the E10.5 Bmp4CFP/t

Fig. 3. CFP signal shows specific Bmp4 expression patterns in developing organs. (A) E10.5 eye. CFP is detected in the dorsal optic cup (arrow). (B) E11.5 forelimb bud, CFP is expressed in the AER (arrow) and the mesodermal regions (arrowheads). (C) Brightfield image of E13.5 lung. (C') CFP view of (C). CFP is specifically elevated in the epithelium cells at the tip of lung buds (arrow heads). (D) Brightfield image of E13.5 heart. (D') CFP view of (D). CFP is expressed in the outflow tract arrow. $L A$, left atrium; $L V$, left ventricle; $R A$, right atrium; $R V$, right ventricle. Orientation: $D$, dorsal; $V m$ ventral; $N$, nasal; $T$, temporal; $A$, anterior; $P$, posterior. Scale bars, $200 \mu \mathrm{m}$. embryo, the CFP signal is present in the eye and is restricted to the dorsal domain of the optic cup, reconfirming the known $B m p 4$ expression pattern (Fig. 2B and $3 \mathrm{~A}$ ). In the developing lung, Bmp4is expressed in the epithelium at the tip of lung buds and plays a key role in branching morphogenesis (Bellusci et al., 1996, Que et al., 2006). The CFP signal in the E13.5 $B m p 4^{C F P /+}$ embryo recapitulates the specific $B m p 4$ expression pattern in the embryonic lung (Fig. 3C'). In the developing heart, $B m p 4$ is expressed in the outflow tract myocardium and endocardial cushion of outflow tract ridges in E12 14 stage embryos and plays an essential role in heart formation (Abdelwahid et al., 2001, McCulley et al., 2008). The CFP signal in the E13.5 $\mathrm{Bmp} 4^{\mathrm{CFP} / \mathrm{t}}$ embryo highlights the outflow tract in the E13.5 heart (Fig. 3D'). In addition, the CFP pattern
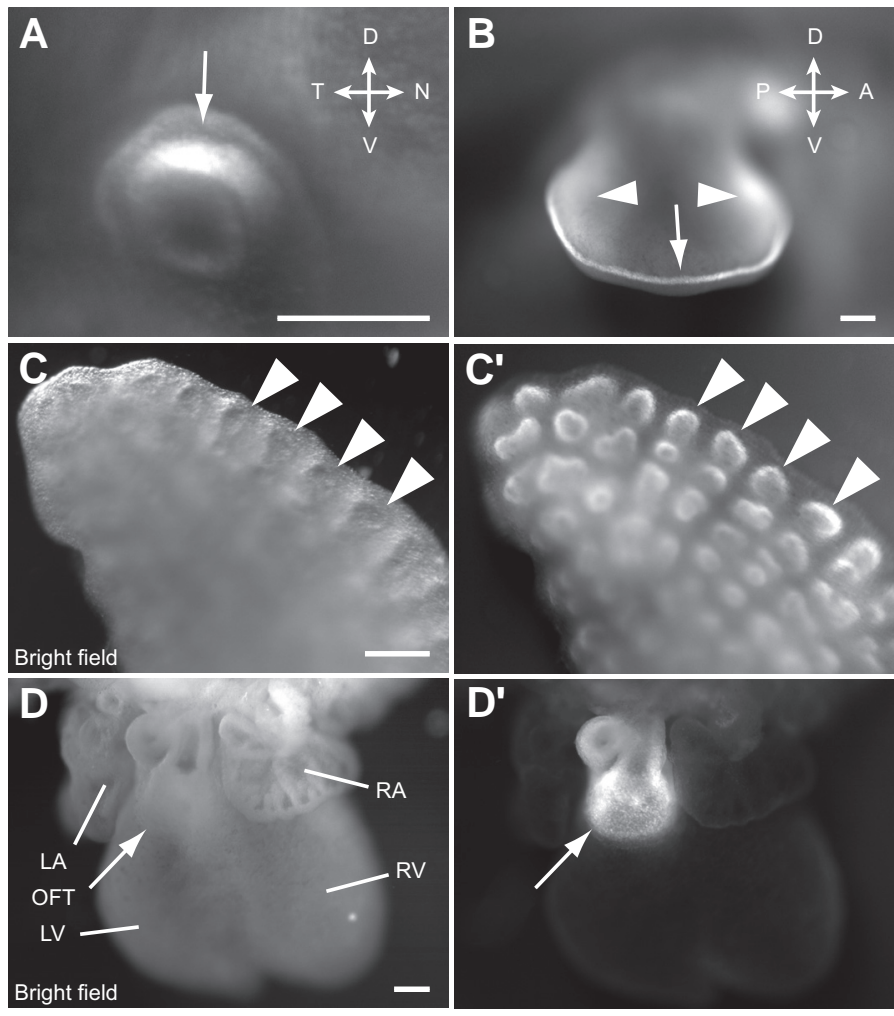
in $B m p 4^{C F P /+}$ embryos also reflects several Bmp4expression domains that have been reported, including the otocyst (Fig. 2B) (Grotewold et al., 2001), branchial arches (Fig. 2B) (Grotewold et al., 2001), nasal pit (Fig. 2C) (Jones et al., 1991), mammary buds (Fig. 2D) (Phippard et al., 1996), vibrassa follicles (Fig. 2E) (Jones et al., 1991, Ozeki et al., 2004), and hair follicles (Fig. 2F) (Botchkarev et al., 1999).

\section{Cellular resolution Bmp4 expression patterns in developing hair follicles}

The development of hair follicles involves complex signaling mechanisms between adjacent tissues, including Wnts (Andl et al., 2002, Reddy et al., 2001), Shh (St-Jacques et al., 1998), Edar (Headon and Overbeek, 1999, Mikkola et al., 1999) and BMPs (Botchkarev and Sharov, 2004), that have been implicated in the initiation, patterning or differentiation of hair follicles. These signaling molecules and some of their antagonists need to be expressed in proper domains and at correct time points for normal hair follicle formation. (Schmidt-Ullrich and Paus, 2005).

Taking advantage of the nuclear localized CFP signal in the $B m p 4^{C F P /+}$ mice that provides precise information of $B m p 4-e x-$ pressing cells, we performed a detailed analysis of the $B m p 4$ expression pattern at different stages of hair follicle development in the embryo. The CFP signal in the ectoderm is initiated between E13.5 and E14.5, forming focal spots in E14.5 embryos (Fig. 2F, $4 A$ and $4 D$ ). This timing correlates with the onset of primary hair placode formation (Schmidt-Ullrich and Paus, 2005). On the skin of E15.5 embryos, the CFP signal outlines many oval-shaped structures with an accompanying brighter spot asymmetrically on one side of each oval ring, and the rings are evenly spaced and surrounded by small focal spots (Fig. 4B and 4E). These ovals with their associated asymmetric spots are coordinately oriented in the same direction. In E16.5 embryos, the CFP signal continues to form more rings with spots, while some bigger rings have their accompanying spot apparently moving further away from the ring (Fig. 4C and 4F). In later stage embryos, the CFP signal basically repeats similar patterns as that in $\mathrm{E} 16.5$ but with more foldings of the skin as the epithelium thickens (data not shown). With confocal microscopy, we observed the nuclear CFP pattern at sub-

Fig. 5. Bmp4 expressing cells form different structures on the skin at different developmental stages. Three-dimensionally reconstructed confocal images of CFP signals provide cellular resolution on Bmp4 expression pattern at different stages. (A) At E14.5, Bmp4-expressing cells form focal spots (red circle) with cells in the center fluorescing more strongly. (B,C) At E15.5, the Bmp4-expressing cells form the ring (yellow circle) and spot (red circle) structures. (D) In more mature hair follicle of E16.5 skin, the bright spot (red circle) appears to move further away from the ring (yellow circle). (A,B,C,D) Views onto the surface of the skin, whereas $\left(\mathbf{C}^{\prime}\right)$ is a tilted view of $(\mathbf{C})$, and $\left(\mathbf{D}^{\prime}\right)$ is a 90 degree rotated view of (D). The spot is actually located beneath the ring in the ring and spot structures, as shown in $\left(C^{\prime}, D^{\prime}\right)$. Ruler numbers indicate length in $\mu \mathrm{m}$.
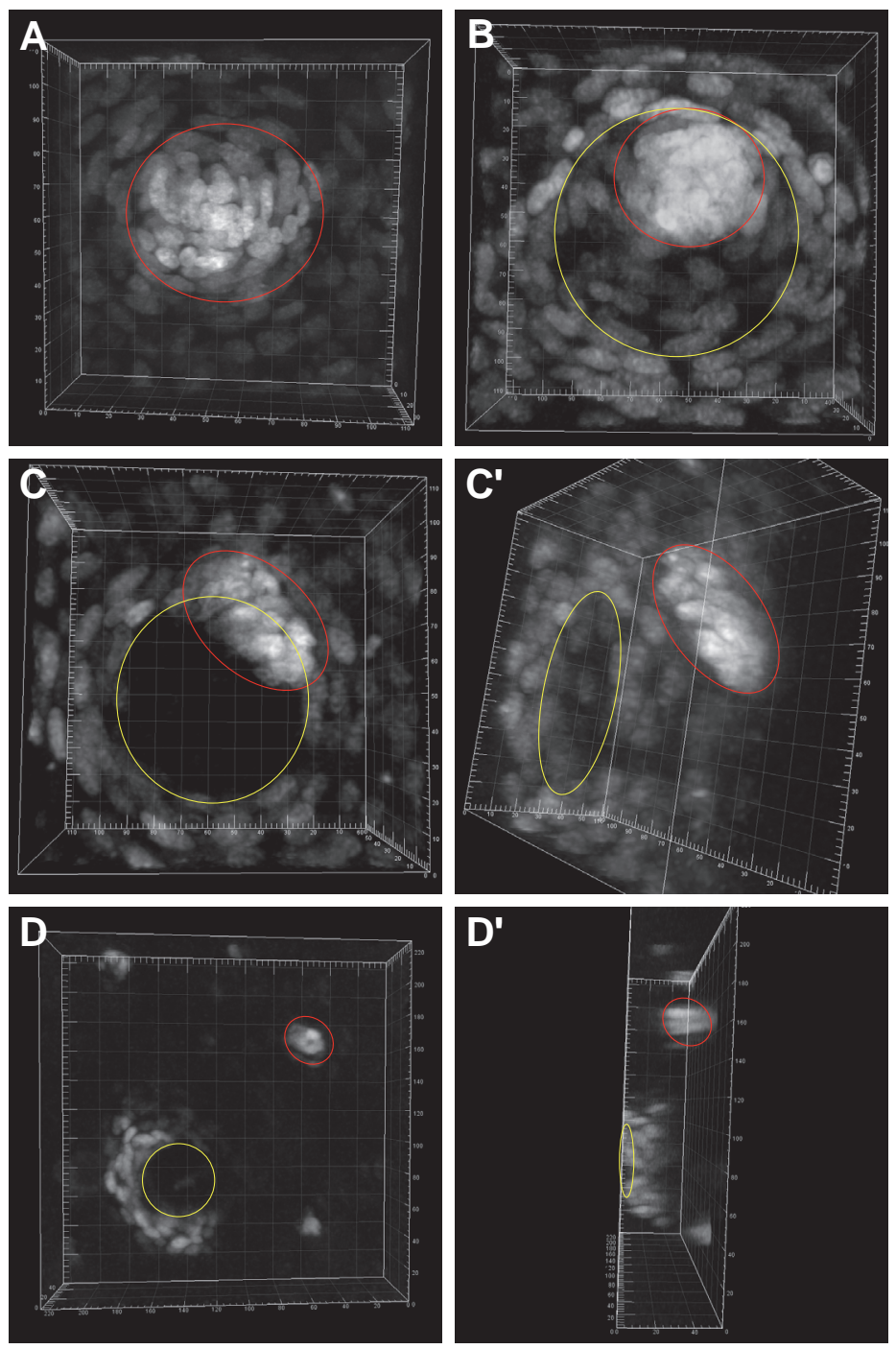
cellular resolution of in live fetal skin and reconstructed three dimensional images. In E14.5 skin, the expression is concentrated in an aggregate of cells, with cells having stronger fluorescence located at the center of every focal spot (Fig. 5A). In E15.5 skin, a ring structure forms with a central region of non-expressing cells surrounded by expressing cells and a group of strongly fluorescing cells residing on one side of the ring (Fig. 5B and $5 \mathrm{C})$. The group of cells with strong signal is actually located beneath the ring of structure, revealed by rotating the reconstructed three-dimensional images $~ 45$ degrees (Fig. 5C'). In E16.5 skin, the bright spot is farther away from the ring (Fig. 5D and $5 \mathrm{D}$ '). We also generated videos rotating the reconstructed images for a better understanding of the structures formed by Bmp4-expressing cells (Supplementary Materials Online). To know the positional relationship of these Bmp4-expressing cells to the developing hair follicles, we made frozen sections of fixed skin tissue. In early stage hair placodes, the Bmp4-expressing cells are in the mesenchymal layer subjacent to the hair placode (Fig. 6A). In more mature hair follicles, Bmp4 is expressed in the dermal papilla of involuted hair follicles (Fig. 6B). The Bmp4-expressing dermal papilla cells eventually become surrounded by non-expressing cells in the bulb structure in late stage hair follicles (Fig. 6C).

\section{Discussion}

We have generated a novel $B m p 4$ allele that expresses a nuclear-localized CFP reporter for live imaging and cellular resolution of $B m p 4$ expression patterns. The observations of CFP signals in various tissues compared with the known pattern of Bmp4 expression show that the CFP signal faithfully reflects the expression pattern of $B m p 4$. Thus, the $B m p 4^{C F P /+}$ mice can be used as an imaging tool to visualize $B m p 4$ expression patterns in live tissues. In addition, Bmp4CFP/t mice provide a novel resource for the isolation of $B m p 4$-expressing cells in live tissues using gross dissection or flow cytometry for the analysis of gene expression profiles or biochemical studies. However, the fluorescent signal is very weak at E8.5 and almost undetectable in E7.5 and earlier stage embryos, although Bmp4 expression is detected at these time points by in situ hybridization or betagalactosidase detection using the lacZknock-in allele (Lawson et al., 1999, Winnier et al., 1995). However, both in situ and betagalactosidase staining techniques detect enzymatically amplified signals and are very sensitive, whereas with the $B m p 4^{C F P}$ allele, the signal strength largely depends on absolute level of fluorescent protein produced and is especially prone to photobleaching at low levels.

We were surprised that the $B m p 4^{C F P}$ allele is functionally a null or very severe hypomorphic allele because in vitro studies of the BMP4-YFP fusion protein in transient tissue culture assays or Xenopus embryos suggested that the fusion protein was active
DAPI
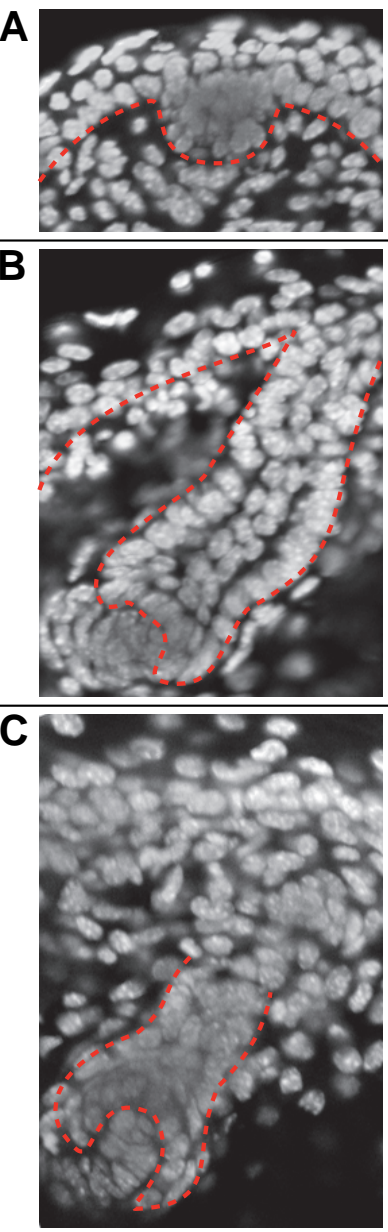

Fig. 6. Bmp4 expressing cells associate with developing hair follicles. Frozen sections of E15.5 (A), E16.5 (B) and E18.5 (C) skin show the respective localization of Bmp4follicles are outlined by red dashed lines. (A) Bmp4 is first expressed by mesenchymal cells (arrow) underneath the hair placode. (B,C) At later stages, the dermal papillae express Bmp4 (arrows). Weaker CFP positive cells are seen near the base of hair follicles (arrowhead in C).
(Jang, Ueno, and Behringer, unpublished observations). In our targeting strategy, no endogenous Bmp4 sequence was deleted in the targeted allele, so that all of the cisregulatory sequences are present. Integration of exogenous sequences into an endogenous locus with exons and introns is different from cDNA expression from plasmids and expression of synthetic mRNA. We speculate that our generation of a null allele may have to do with expression and/or mRNA processing from a genomic locus. It is possible that the YFP-tagged BMP4 protein is destabilized in vivo, and this stability issue was masked by overexpression in cell culture and Xenopus embryos. In addition, western blot analysis of protein extracts from tissues of $B m p 4^{C F P /+}$ embryos shows a very weak or undetectable YFP-BMP4 fusion protein band (data not shown).

We summarize our findings of $B m p 4$ expression in the embryonic skin using the $B m p 4^{C F P}$ allele in Fig. 7 . In E13.5 skin, prior to hair placode formation, Bmp4expression is not detected. In E14.5 skin, placodes begin to form and Bmp 4 is expressed by mesenchymal cells underneath the placodes. In E15.5 skin, as the 
E13.5

(stage 0)
E15.5

(stage 2)
E16.5 17.5
(stage 3 5)

(stage 1)

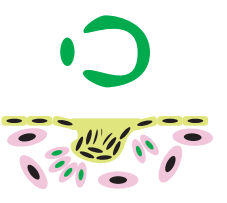

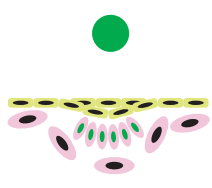

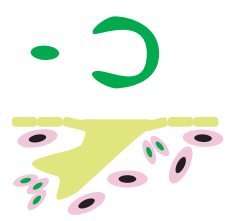

E18.5 (stage 6 8)

Fig. 7. Summary of Bmp4-expressing cells in different stage hair follicles. BMP4 expressing cells are marked by green nuclei. At E14.5, the aggregated Bmp4expressing cells underneath initiating hair placode are seen as spots on the skin. At E15.5, the ring and spot pattern comes from the strong expressing cells below the tip of invaginating hair follicle. At E16.5 and later stages, the Bmp4-expressing cells form the dermal papilla and surround the base of hair follicles. The schematic hair follicle developmental stage diagram in this figure is modified from the review by Schmidt-Ullrich and Paus, 2005. epithelial cells in primary hair follicles start to invaginate, cells with stronger Bmp4 expression form a cap structure at the tip of the invaginated epithelium structure with a ring of $B m p 4$-expressing cells surrounding the invagination at the base. At E16.5, Bmp4 is expressed in the dermal papilla adjacent to the tip of hair follicles that are extending further into dermis. At E18.5, Bmp4expression is maintained in the dermal papilla cells surrounded in the bulb structure in late stage hair follicles.

The suppressive activity of BMPs on hair placode formation has been implicated in different experimental systems (Botchkarev et al., 1999, Jung et al., 1998, Noramly and Morgan, 1998). In addition, the importance of the BMP signaling pathway in specification of different cell types in the hair follicle has been well documented (Botchkarev and Sharov, 2004). The ring-shaped expression pattern of developing hair follicles is quite unique, among other signaling molecules that are expressed in the hair follicle and required for proper development (Laurikkala et al., 2002, Mou etal., 2006). This may reflect a unique role BMP4 plays or the advantage of using fluorescent protein labeling technique since many gene expression patterns have only been examined on sections on which the three dimensional structure is not easily noticed. It will be interesting to determine how the dynamic Bmp4expressing cell rings and focal aggregates that we have discovered relate to these inductive and differentiation roles of BMP4 during hair follicle development.

Here we have shown the feasibility of visualizing $B m p 4$ expression in live tissues with our knock-in allele, and analyzed $B m p 4$ expressing domains associated with developing hair follicles. This allele provides a new experimental tool for studying BMP4 signaling mechanisms in live tissues. In addition, BMP reporter transgenic mouse lines that express EGFP in BMP signal-receiving cells have been created (Blank et al., 2008, Monteiro et al., 2008). EGFP and CFP are spectrally distinguishable (Dickinson et al., 2002, Lansford et al., 2001, Zimmermann, 2005). The possibility of combining our Bmp4CFP allele with the BMP signaling GFP reporter lines may further advance the study of BMP signaling by live tissue imaging techniques.

\section{Materials and Methods}

\section{Generation of Bmp4 ${ }^{\mathrm{CFP}}$ knock-in allele in the mouse}

The targeting construct was generated by subcloning a $2.1-\mathrm{kb} 5$, homologous region upstream from the endogenous start site of $B m p 4$ to fuse with a human histone $\mathrm{H} 2 \mathrm{~b}$-Cerulean (an improved CFP) coding sequence (Hadjantonakis and Papaioannou, 2004, Rizzo et al., 2004), followed by a self-cleavage $2 \mathrm{~A}$ sequence from the virus Thosea asigna (Szymczak and Vignali, 2005), followed by the endogenous coding sequence for BMP4 as an in-frame fusion. A floxed Pgk-neo-bpA cassette [from pL452 (Liu et al., 2003)] was inserted into the Eco RI site into the preserved third intron in reverse orientation. An improved YFP, Citrine (Griesbeck et al., 2001), coding sequence was inserted into the fourth exon as an in-frame fusion after the furin cleavage site that generates the mature peptide. An additional homologous region of $3.3 \mathrm{~kb}$ was included in the targeting construct after the Citrine coding sequence. In our targeting strategy, no endogenous sequence was deleted. An MC1-TK cassette was placed next to the 3' homologous region for negative selection. G4 ES cells (George et al., 2007) were electroporated with linearized targeting construct DNA and subjected to G418 and FIAU double drug selection. Surviving clones were screened by Southern blotting with BamHI enzyme digestion of genomic DNA. A 1-kb 5' probe and a 1.4-kb 3' probe outside of the homologous region on the targeting construct were used to identify correctly targeted clones. One of these clones was expanded and injected into $\mathrm{C} 57 \mathrm{BI} / 6 \mathrm{~J}$ blastocysts to generate chimeras. The floxed Neo cassette was removed through crossing with Sox2-Cre transgenic animals (Hayashi et al., 2003). Heterozygous animals carrying the CFP knock-in Bmp4 allele without Neo are maintained on an outbred SWISS Webster (Taconic, NY) genetic background and used for analysis in this report.

Primers for PCR-genotyping animals:

Set A: BMP4-F1: 5'-GAAGCCACGCTGAGATCATGGC;

BMP4-R1: 5'-CATCTGTAGAAGTGTCGCCTCGAAG;

CFP-R: 5'-CGGACACGCTGAACTTGTGG;

LacZ-R: 5'-ACGACAGTATCGGCCTCAGGAAG.

Set B: BMP4-F2: 5'-GCTAGCTGCTCCACAACTCTACTC;

BMP4-R2: 5'-TGCCGAGGAGATCACCTCATTCTC;

Pgk-R1: 5'-CACCAAAGAACGGAGCCGGTTG.

$P C R$ genotyping with Primer Set $A$ with $60.5^{\circ} \mathrm{C}$ annealing temperature generates a 550-bp product from the wild-type Bmp4 allele, a 700-bp product from the null lacZknock-in allele (Lawson et al., 1999), or an 850bp product from the CFP knock-in allele. PCR genotyping with Primer Set $B$ with $55^{\circ} \mathrm{C}$ annealing temperature generates a 320-bp product for the wild-type allele, a 500-bp product for the floxed Neo cassette in the CFP allele, or a 400-bp product for the footprint loxP site after $\mathrm{Neo}$ is removed by Cre recombinase.

\section{Imaging of CFP expression patterns in live and fixed tissues}

For live imaging of whole embryos, embryos of desired stages were isolated from the uterus of pregnant females from timed matings. Embryos were immersed in phosphate buffered saline (PBS) and imaged at low magnification with a Carl Zeiss Lumar fluorescent stereo microscope system (http://www.zeiss.de/). Lungs and heart were dissected from E13.5 embryos for imaging with the same settings. For higher resolution CFP confocal images of the skin, live embryos were placed on a glass bottom dish with PBS and imaged with a Zeiss LSM 510 META laser confocal microscopy system, using a C-Apochromat 40X/W, NA=1.2 Corr objective (Carl Zeiss Inc.). Three-dimensional images were reconstructed using the image processing software Imaris 5.0.3 (Bitplane, St. Paul, MN, USA) (http://www.bitplane.com/).

For frozen sections of skin, whole embryos were fixed in $4 \%$ paraformaldehyde in phosphate buffered saline for one hour and washed through 
$10 \%, 20 \%$ and $30 \%$ sucrose solutions, and then embedded in O.C.T. compound [Tissue-Tek (http://www.tedpella.com/)]. Sections were mounted with DAPI containing medium and then imaged with the same laser confocal microscopy system and objective as that for live skin imaging.

\section{Acknowledgements}

We thank Jim Martin for providing Bmp4 genomic DNA plasmids, Andras Nagy for the G4 mouse ES cells, Jian Min Deng for tissue culture assistance, and Henry Adams for advice on microscopy. Supported by National Institutes of Health (NIH) grants NIH HLO77187 and EB005173 to M.E.D and NIH HD30284 and the Ben F. Love Endowment to R.R.B. $D N A$ sequencing and veterinary resources were supported by the NIH Cancer Center Support Grant CA16672.

\section{References}

ABDELWAHID, E., RICE, D., PELLINIEMI, L.J. and JOKINEN, E. (2001). Overlapping and differential localization of Bmp-2, Bmp-4, Msx-2 and apoptosis in the endocardial cushion and adjacent tissues of the developing mouse heart. Cell Tissue Res 305: 67-78.

ANDL, T., REDDY, S.T., GADDAPARA, T. and MILLAR, S.E. (2002). WNT signals are required for the initiation of hair follicle development. Dev Cel/2: 643-53.

BANDYOPADHYAY, A., TSUJI, K., COX, K., HARFE, B.D., ROSEN, V. and TABIN, C.J. (2006). Genetic analysis of the roles of BMP2, BMP4, and BMP7 in limb patterning and skeletogenesis. PLOS Genet2: e216.

BEHESTI, H., HOLT, J.K. and SOWDEN, J.C. (2006). The level of BMP4 signaling is critical for the regulation of distinct T-box gene expression domains and growth along the dorso-ventral axis of the optic cup. BMC Dev Bio/6: 62.

BELLUSCI, S., HENDERSON, R., WINNIER, G., OIKAWA, T. and HOGAN, B.L. (1996). Evidence from normal expression and targeted misexpression that bone morphogenetic protein (Bmp-4) plays a role in mouse embryonic lung morphogenesis. Development 122: 1693-702.

BITGOOD, M.J. and MCMAHON, A.P. (1995). Hedgehog and Bmp genes are coexpressed at many diverse sites of cell-cell interaction in the mouse embryo. Dev Bio/172: 126-38.

BLANK, U., SETO, M.L., ADAMS, D.C., WOJCHOWSKI, D.M., KAROLAK, M.J. and OXBURGH, L. (2008). An in vivo reporter of BMP signaling in organogenesis reveals targets in the developing kidney. BMC Dev Bio/8: 86.

BOTCHKAREV, V.A., BOTCHKAREVA, N.V., ROTH, W., NAKAMURA, M., CHEN, L.H., HERZOG, W., LINDNER, G., MCMAHON, J.A., PETERS, C., LAUSTER, R. et al. (1999). Noggin is a mesenchymally derived stimulator of hair-follicle induction. Nat Cell Bio/1: 158-64.

BOTCHKAREV, V.A. and SHAROV, A.A. (2004). BMP signaling in the control of skin development and hair follicle growth. Differentiation 72: 512-26.

DERYNCK, R. and ZHANG, Y.E. (2003). Smad-dependent and Smad-independent pathways in TGF-beta family signalling. Nature 425: 577-84

DICKINSON, M.E., WATERS, C.W., WOLLESCHENSKY, R., BEARMAN, G., TILLE, S. and FRASER, S.E. (2002). Sensitive imaging of spectrally overlapping fluorochromes using the LSM 510 META. In Multiphoton Microscopy in the Biomedical Sciences, vol. 4620 (ed. PERIASAMY, A. and SO, P. T.), pp. 123136: Proceedings of the International Society for Optical Engineering (SPIE).

FURUTA, Y. and HOGAN, B.L. (1998). BMP4 is essential for lens induction in the mouse embryo. Genes Dev 12: 3764-75.

GEORGE, S.H., GERTSENSTEIN, M., VINTERSTEN, K., KORETS-SMITH, E., MURPHY, J., STEVENS, M.E., HAIGH, J.J. and NAGY, A. (2007). Developmental and adult phenotyping directly from mutant embryonic stem cells. Proc Natl Acad Sci USA 104: 4455-60.

GRIESBECK, O., BAIRD, G.S., CAMPBELL, R.E., ZACHARIAS, D.A. and TSIEN, R.Y. (2001). Reducing the environmental sensitivity of yellow fluorescent protein. Mechanism and applications. J Biol Chem 276: 29188-94.

GROTEWOLD, L., PLUM, M., DILDROP, R., PETERS, T. and RUTHER, U. (2001). Bambi is coexpressed with Bmp-4 during mouse embryogenesis. Mech Dev 100: 327-30.

HADJANTONAKIS, A.K. and PAPAIOANNOU, V.E. (2004). Dynamic in vivo imag- ing and cell tracking using a histone fluorescent protein fusion in mice. BMC Biotechno/4: 33.

HAYASHI, S., TENZEN, T. and MCMAHON, A.P. (2003). Maternal inheritance of Cre activity in a Sox2Cre deleter strain. Genesis 37: 51-3.

HEADON, D.J. and OVERBEEK, P.A. (1999). Involvement of a novel Tnf receptor homologue in hair follicle induction. Nat Genet 22: 370-4.

HOGAN, B.L. (1996). Bone morphogenetic proteins: multifunctional regulators of vertebrate development. Genes Dev 10: 1580-94.

JONES, C.M., LYONS, K.M. and HOGAN, B.L. (1991). Involvement of Bone Morphogenetic Protein-4 (BMP-4) and Vgr-1 in morphogenesis and neurogenesis in the mouse. Development 111: 531-42.

JUNG, H.S., FRANCIS-WEST, P.H., WIDELITZ, R.B., JIANG, T.X., TING-BERRETH, S., TICKLE, C., WOLPERT, L. and CHUONG, C.M. (1998). Local inhibitory action of BMPs and their relationships with activators in feather formation: implications for periodic patterning. Dev Biol196: 11-23.

LANSFORD, R., BEARMAN, G. and FRASER, S.E. (2001). Resolution of multiple green fluorescent protein color variants and dyes using two-photon microscopy and imaging spectroscopy. J Biomed Opt 6: 311-8.

LAURIKKALA, J., PISPA, J., JUNG, H.S., NIEMINEN, P., MIKKOLA, M., WANG, X., SAARIALHO-KERE, U., GALCERAN, J., GROSSCHEDL, R. and THESLEFF, I. (2002). Regulation of hair follicle development by the TNF signal ectodysplasin and its receptor Edar. Development 129: 2541-53.

LAWSON, K.A., DUNN, N.R., ROELEN, B.A., ZEINSTRA, L.M., DAVIS, A.M., WRIGHT, C.V., KORVING, J.P. and HOGAN, B.L. (1999). Bmp4 is required for the generation of primordial germ cells in the mouse embryo. Genes Dev 13 : 424-36.

LIU, P., JENKINS, N.A. and COPELAND, N.G. (2003). A highly efficient recombineering-based method for generating conditional knockout mutations. Genome Res 13: 476-84.

MAATOUK, D.M., CHOI, K.S., BOULDIN, C.M. and HARFE, B.D. (2009). In the limb $\mathrm{AER}$ Bmp2 and Bmp4 are required for dorsal-ventral patterning and interdigita cell death but not limb outgrowth. Dev Biol.

MCCULLEY, D.J., KANG, J.O., MARTIN, J.F. and BLACK, B.L. (2008). BMP4 is required in the anterior heart field and its derivatives for endocardial cushion remodeling, outflow tract septation, and semilunar valve development. Dev Dyn 237: $3200-9$

MIKKOLA, M.L., PISPA, J., PEKKANEN, M., PAULIN, L., NIEMINEN, P., KERE, J. and THESLEFF, I. (1999). Ectodysplasin, a protein required for epithelia morphogenesis, is a novel TNF homologue and promotes cell-matrix adhesion. Mech Dev 88: 133-46.

MONTEIRO, R.M., DE SOUSA LOPES, S.M., BIALECKA, M., DE BOER, S. ZWIJSEN, A. and MUMMERY, C.L. (2008). Real time monitoring of BMP Smads transcriptional activity during mouse development. Genesis 46: 335-46.

MOU, C., JACKSON, B., SCHNEIDER, P., OVERBEEK, P.A. and HEADON, D.J. (2006). Generation of the primary hair follicle pattern. Proc Natl Acad Sci USA 103: $9075-80$.

NORAMLY, S. and MORGAN, B.A. (1998). BMPs mediate lateral inhibition at successive stages in feather tract development. Development 125: 3775-87.

OZEKI, H., KURIHARA, Y., TONAMI, K., WATATANI, S. and KURIHARA, H (2004). Endothelin-1 regulates the dorsoventral branchial arch patterning in mice. Mech Dev 121: 387-95.

PHIPPARD, D.J., WEBER-HALL, S.J., SHARPE, P.T., NAYLOR, M.S., JAYATALAKE, H., MAAS, R., WOO, I., ROBERTS-CLARK, D., FRANCIS WEST, P.H., LIU, Y.H. et al. (1996). Regulation of Msx-1, Msx-2, Bmp-2 and Bmp-4 during foetal and postnatal mammary gland development. Development 122: $2729-37$.

QUE, J., CHOI, M., ZIEL, J.W., KLINGENSMITH, J. and HOGAN, B.L. (2006) Morphogenesis of the trachea and esophagus: current players and new roles for noggin and Bmps. Differentiation 74: 422-37.

REDDY, S., ANDL, T., BAGASRA, A., LU, M.M., EPSTEIN, D.J., MORRISEY, E.E. and MILLAR, S.E. (2001). Characterization of Wnt gene expression in developing and postnatal hair follicles and identification of Wnt5a as a target of Sonic hedgehog in hair follicle morphogenesis. Mech Dev 107: 69-82.

RIZZO, M.A., SPRINGER, G.H., GRANADA, B. and PISTON, D.W. (2004). An improved cyan fluorescent protein variant useful for FRET. Nat Biotechno/22 445-9. 
SCHMIDT-ULLRICH, R. and PAUS, R. (2005). Molecular principles of hair follicle induction and morphogenesis. Bioessays 27: 247-61.

SELEVER, J., LIU, W., LU, M.F., BEHRINGER, R.R. and MARTIN, J.F. (2004). Bmp4 in limb bud mesoderm regulates digit pattern by controlling AER development. Dev Bio/276: 268-79.

ST-JACQUES, B., DASSULE, H.R., KARAVANOVA, I., BOTCHKAREV, V.A., LI, J., DANIELIAN, P.S., MCMAHON, J.A., LEWIS, P.M., PAUS, R. and MCMAHON, A.P. (1998). Sonic hedgehog signaling is essential for hair development. Curr Bio/8: 1058-68.

SZYMCZAK, A.L. and VIGNALI, D.A. (2005). Development of 2A peptide-based strategies in the design of multicistronic vectors. Expert Opin Biol Ther5: 627-38.

TELEMAN, A.A. and COHEN, S.M. (2000). Dpp gradient formation in the Drosophila wing imaginal disc. Cel/103: 971-80.

WINNIER, G., BLESSING, M., LABOSKY, P.A. and HOGAN, B.L. (1995). Bone morphogenetic protein-4 is required for mesoderm formation and patterning in the mouse. Genes Dev 9: 2105-16.

ZHAO, G.Q. (2003). Consequences of knocking out BMP signaling in the mouse. Genesis 35: 43-56.

ZIMMERMANN, T. (2005). Spectral imaging and linear unmixing in light microscopy. Adv Biochem Eng Biotechno/95: 245-65.

\section{Further Related Reading, published previously in the Int. J. Dev. Biol.}

See Special Issue Pattern Formation edited by Michael K. Richardson and Cheng-Ming Chuong at: http://www.ijdb.ehu.es/web/contents. php?vol=53\&issue $=5-6$

\section{Analyses of regenerative wave patterns in adult hair follicle populations reveal macro- environmental regulation of stem cell activity}

Maksim V. Plikus, Randall B. Widelitz, Rob Maxson and Cheng-Ming Chuong

Int. J. Dev. Biol. (2009) 53: 857-868 (doi: 10.1387/ijdb.072564mp)

\section{Frontiers in fluorescence microscopy}

José Rino, José Braga, Ricardo Henriques and Maria Carmo-Fonseca

Int. J. Dev. Biol. (2009) 53: 1569-1579 (doi: 10.1387/ijdb.072351jr)

Transdifferentiation of corneal epithelium: evidence for a linkage between the segregation of epidermal stem cells and the induction of hair follicles during embryogenesis

David J Pearton, Corinne Ferraris and Danielle Dhouailly

Int. J. Dev. Biol. (2004) 48: 197-201

Hair follicle differentiation and regulation.

George E Rogers

Int. J. Dev. Biol. (2004) 48: 163-170

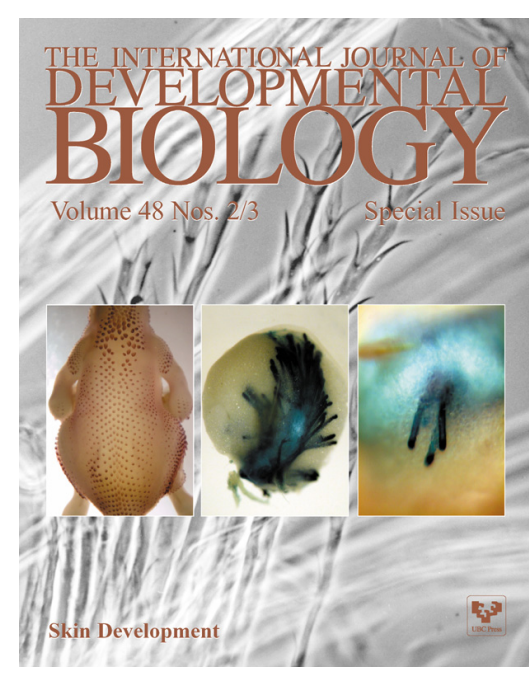

5 yr ISI Impact Factor $(2008)=3.271$
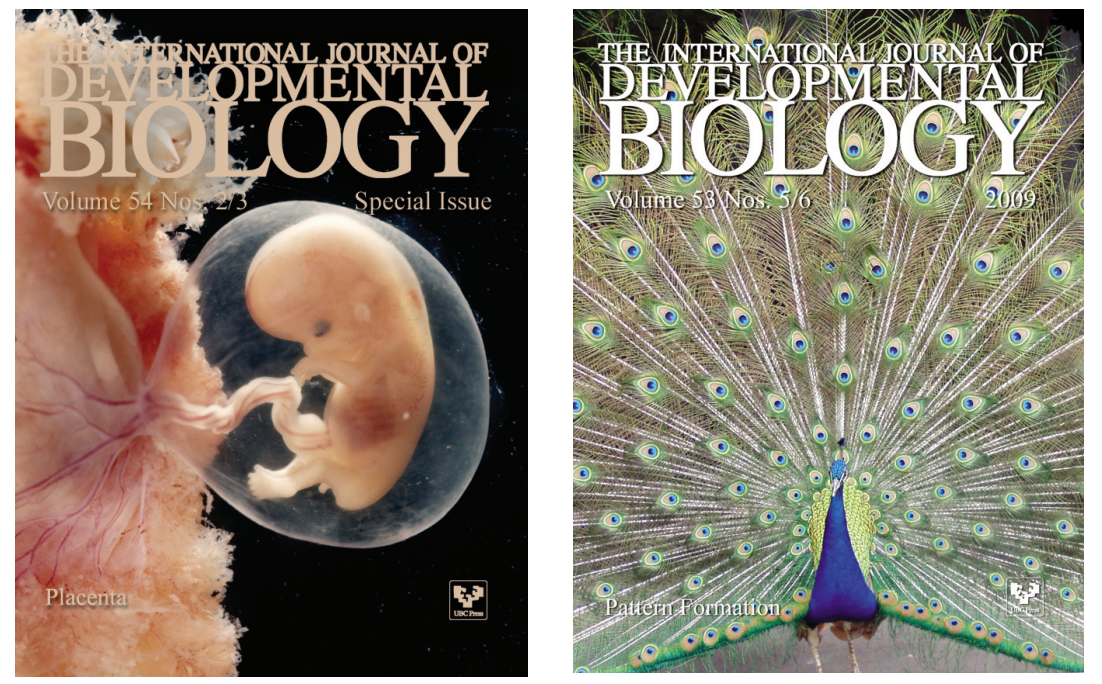